Canadian Oncology

Nursing Journal

Revue canadienne

de soins infirmiers

en oncologie

Volume 31, Issue 2 • Spring 2021

elSSN: 2368-8076 


\section{Incorporating reflective writing \& art therapy in my palliative care practice}

\section{by Kalliopi (Kalli) Stilos and Katherine Burgoyne}

Key words: reflective writing, palliative care, arts-based therapy

\section{INTRODUCTION AND BACKGROUND}

$\mathrm{T}$ The specialty of palliative care routinely focuses on the complex needs of patients living with incurable illness and their families' emotional and psychosocial concerns. Healthcare professionals who work with patients with advanced illness sometimes suffer from frustration and anxiety when they return home from caring for dying patients. The psychosocial care that increases patient and family satisfaction is sometimes lost when nurses are suffering (Pendry, 2007; Freeman, 2013). Continuous exposure to such difficult situations and the accumulation of unrecognized feelings and attitudes can lead to physical and psychological challenges (Pereira et al., 2011). As such, nurses have a duty to maintain their health to the best of their ability. To encourage nurses in promoting emotional health, Freeman's (2013) CARES tool (Comfort, Airway management, Restlessness and delirium, Emotional and spiritual support, and Self-care) was integrated into our organization's Comfort Measures Order Set for imminently dying patients (prognosis $<72$ hours) (Stilos, Wynntchuk et al., 2016).

Stilos and Wynnychuk, (in press) outlined the importance of self-care for healthcare professionals and several self-care practices in which one can partake both personally and professionally (Chittenden \& Ritchie, 2011). Personal self-care

\section{AUTHOR NOTES}

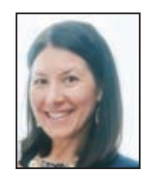

Kalliopi (Kalli) Stilos, RN, MScN, CHPCA(C), Advance Practice

Nurse for the In-Patient Palliative Care Consult Team

Adjunct Clinical Faculty, University of Toronto's Lawrence

Bloomberg Faculty of Nursing, Sunnybrook Health Science

Centre, 2075 Bayview Avenue, Toronto, ON M4N 3M5 H337

kalli.stilos@sunnybrook.ca

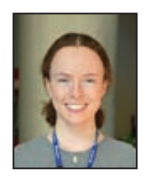

Katherine Burgoyne, RP (Registered Psychotherapist), MSc (In Art Therapy), Recreation Therapy \& Creative Arts Therapies Department in the Veterans Centre, Sunnybrook Health Science Centre, 2075 Bayview Avenue, Toronto, ON M4N 3M5 H337 Katherine.Burgoyne@sunnybrook.ca

Corresponding author: Kalli Stilos kalli.stilos@sunnybrook.ca

DOI:10.5737/23688076312205212 includes prioritizing relationships with our families, our loved ones, and our community and may include maintaining a healthy lifestyle regular exercise, vacations, hobbies, and work-life balance (Bowman 2007; Dyrbey et al., 2011; Shanafelt et al., 2005). Professional self-care strategies include mindfulness and meditation, reflective writing, reciting a saying, and pursuing spiritual development (Cohen-Katz et al., 2004; Puchalski \& Guenther, 2012); all undertaken in the effort of mitigating "burnout, moral distress, and compassion fatigue" (Sanchez-Reilly et al., 2013, p. 75). It has been noted that reflective writing is also beneficial in reducing stress and promoting physical and emotional well-being, which then enhances one's compassion and may benefit patient and families (Halifax, 2014). In the setting of caring for patients with advanced illness-whose situation can be afflicted with a combination of physical, emotional, psychosocial, and spiritual suffering and often unchangeable challenge-practitioners can engage in these repetitive self-care strategies. Many times, one of the clinician's roles is to bear witness to the suffering and be an active listener to patients' moving stories that, at times, can be overwhelming.

A key recommendation is that the professional self-care strategy chosen is one that is regularly practised and has a component of self-reflection imbedded to deepen one's sense of self-awareness and engagement, along with one that will build supportive relationships with mentors and colleagues (Rokach, 2005). Developing self-awareness, defined as a clinician's ability to combine self-knowledge with the dual awareness of his/her own subjective experience and the needs of the patient, is critically important and deserves attention in the arena of self-care (Sanchez-Reilly, 2013). Through reflection, a deeper awareness and understanding of the self and the situations one encounters is possible (Moore \& Daines, 2017). This understanding can then inform and enhance future encounters in similar situations. Reflective writing is a tool that may enhance self-awareness and promote reflection (Brady et al., 2002). Reflection is an important component of practisng in the specialty of palliative care. It has become incorporated into many medical and nursing programs and hospitals (Jarvis, 1992; Braun et al., 2013; RNAO, 2017; Mills et al., 2017) and can support the development of a professional identity (Shapiro, Kasman, \& Shafter, 2006).

Kalli's journey with reflective writing began after the initiation of a reflective practice module for medical learners during their one month-long rotation with the Palliative Care Consult Team. The objective of the module was to promote reflection and self-awareness through the use of reflective writing (Moore \& Daines, 2017). The module has evolved since it was first launched by Moore and Daines. Upon 
Patricia Daines' retirement, Kalli took over as the nursing facilitator of the module. The module continues to start with selected pre-readings, which introduce learners to the concept of reflection and then continues with a reflective writing exercise and sharing of the writings. Medical learners are no longer asked to submit their writings to the facilitators for individual feedback to their reflective writings. The current reflective writings exercise is based on Spann's (2004) method, "keep the pen moving, welcome everything; don't worry about errors; let the subject choose you; write for your eyes only; feelings, feelings, feelings; and details, details, details" (p. 1162). Learners are given the following prompt: "Think of a time when you found yourself in the presence of someone's suffering. This may have been a clinical situation or a personal one." All learners, including facilitators, are given five minutes to write. Comparable prompts were given to the learner. An opportunity for sharing one's story follows, but sharing among the group is entirely voluntary. Kalli describes the experience below:

As one of the facilitators, I always participate and read my written reflection and welcome the learners' feedback or comments. Knowing that these sessions are monthly, I decided that I needed to have stories to share with learners. Kearney et al.'s (2009) suggested self-care and self-awareness practice in the workplace entailed, "keeping a notebook and write 'field notes' on traumatic or meaningful encounters and events; occasionally taking time at interdisciplinary team meetings to share this material" (p. 1161). This suggestion has since inspired me with my newfound practice that allows me to make meaning of the suffering that I encounter each day. This strategy is in keeping with the viewpoint expressed in Clandin et al. (2011), that reflective writing is grounded in personal experiences that lend themselves to the writer reviewing and making sense of experiences to attain deeper meaning and understanding. Teunissen et al. (2007) also described the benefits reflective writing has had on residents, most specifically how it has helped them learn from their clinical experiences. As most learners do not take on reflective learning practices instinctively, clinical educators must help them (Ertmer \& Newby, 1996). Therefore, clinical educators are tasked with stimulating "students to assess and analyze their actions systematically and critically and formulate alternative actions" (Driessen et al., 2008, p. 829). Additionally, this process of role-modeling self-reflection for learners has been positive and enriching to my palliative care work, as was also described by Moore and Daines (2017).

Below are five reflective writings that were written by Kalli for the purpose of the reflective writing module and to share with learners. They have been edited for the purpose of this journal article and have been anonymized. In addition, the author of the stories decided to take reflection one step further by collaborating with an art therapist, Katherine B., who was instrumental in capturing the essence of the stories with her art.

\section{No One Should Have to Clean Me Up!}

We take being able to toilet independently for granted, until one day we cannot do it on our own. Such a routine phenomenon that we don't think twice about; and yet, when patients find themselves in that state, it's the one thing they ruminate over. Recently, I had a burly, 250 lb., blue-eyed, bald-headed, 52-year-old gentlemen with a Glioblastoma diagnosis who experienced the loss of independent toileting. Never did he ever imagine that this would happen to him in his $50 \mathrm{~s}$.

His guileless frosty blue eyes and right facial droop greet me at every bedside visit, always with a hint of embarrassment in the air. Palliative care was recommended to support this patient with pain and symptom issues related to his recent biopsy of his frontal lobe mass and his upcoming radiation. Additionally, goals of care discussions will need to take place, as his prognosis is sadly likely less than a year. Radiation oncology planned for 10 fractions to his brain. Some patients can become symptomatic from radiation therapy, thus it's always best to involve our palliative team early when possible. A first visit entails a thorough pain and symptom screening assessment. He described headaches and radiating pain from his biopsy site as "sharp shooting pain that pierces down his right eye and into his cheek bone". He also experienced diplopia through the right eye causing dizziness and difficulty focusing. The symptom assessment check list also covers nausea and bowel routines. He hesitated to respond. I stood over his bed in an awkward silence. Most patients will utter they are either constipated, they have no issues and have daily bowel motions, or they share their elaborate home bowel concoction. He responded with, “Didn't you hear? I had an explosion the other day in my bed! I soiled everything. I hadn't gone for one week from the time I got into hospital. They gave me this liquid, red sweet stuff, then a suppository, and finally a fleet enema. It cleaned everything out of me. I can't get myself to the washroom and wipe myself. Is this how my life will be moving forward?" How does his nurse, standing in front of him, help him reconcile that yearning when I'm still able to perform such a routine task? The patient was transferred to the oncology floor where he would remain an inpatient for his radiation, as coming to and from hospital would be impossible with his physical limitations not being able to weight bear.

Once again, I follow him through his treatment, assessing his pain and symptoms. All symptoms were controlled except his bowel movements. Once again, a week passed since his last one according to the nursing documentation record. I provided him with education on the fact that opioids are constipating and that we would need to adjust his bowel protocol. He declined the changes we suggested out of fear of reliving the explosive bowel incident. I sat down in the chair next to his bed and I started to explore his feelings. He stated how undignified it was to have a bowel movement in bed. A bedpan sat on the windowsill in hopes of getting him 
on it earlier in the day. He asked, "Can I see it?" He took it in his hands and examined it with curiosity, like a kid in science class examining a leaf under a microscope for the first time.

I said, "It resembles the shape of a cowboy hat." He agreed and we both laughed. In the last few years, the hospital transitioned to cardboard, biodegradable, one-time use urinals and bedpans. I find the new bedpans not as deep as the plastic or metal ones we used in the past. I, too, always wonder whether these new ones will hold the patients' weight. He joked, "What I have inside of me can't hold that. I guess I don't have a choice? If we are to start this process, let's do it soon so I don't have an accident on the radiation table. The least that you can do for me is have my roommate give me my privacy."

Sometimes it is the smallest interventions of understanding their perspective and giving them back a little sense of control that creates the conduit they need to help themselves.

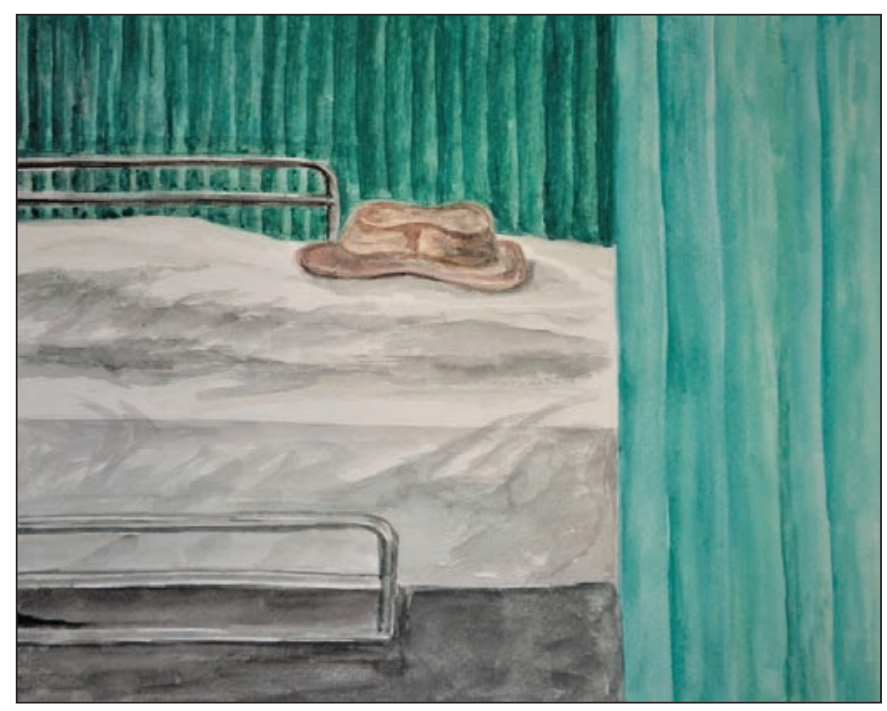

\section{Ostomy and Odours}

At 48, she was diagnosed with ovarian cancer. She underwent several lines of chemo and radiation. This time a bowel obstruction brought her into hospital. An unresectable bowel obstruction has a poor prognosis. I know she didn't know that yet. Palliative care was consulted to assess her for pain and other symptoms that arise from such a diagnosis.

I enter room 42 on the oncology ward to find a heavyset lady with salt and pepper hair lying in the hospital bed. I introduce myself and outline why I came to see her. She wanted nothing to do with our service once I told her I was from palliative care. I repeat myself and explain to Melanie the rationale for the consult, and that our team was consulted to provide symptom management options while she waited for a general surgery opinion for a possible diverting colostomy. She gave me such cold-hearted replies to all my questions. I felt I deserved better, as all I wanted to do was help her. I wonder if she was harboring anger and just projecting it toward me. After years of providing clinical care and finding myself in similar situations, I have learned over time you need to develop thick skin during such encounters to keep from getting upset. However, I continuously find myself caught off guard with such strong reactions and ask myself, do patients forget that the healthcare provider before them has not put them in the unfortunate situation they find themselves in, but the cancer has? I kept my composure and worked through the patient's anger in order to provide effective care and build that necessary nurse-patient therapeutic relationship. The first visit ended with ordering symptom management medications. The following day surgery was confirmed, and she was added to the OR list.

The following day, Melanie came across softer and started opening up about herself. I welcomed it with pleasure, as it is always more clinically rewarding when patients like to share a glimpse of their life with me.

She began with, "I'm a mother of two five-year-old identical twin girls", which I had read in the social history. I asked her their names and whether she had pictures of them. A smile appeared and, in a flash, she had pulled out her iPhone from under the blanket. She started scrolling through a few of the hundred pictures that were stored. "This is Lilly, and this is Ave". They were both beautiful blonde-haired girls with blue eyes, just precious beauties. One had pinstripe hair and round glasses and the other had Goldilocks curls. They had permanent smiles in most of the pictures she scrolled through. I went on to probe, "So what is your favourite activity with the girls?" She responds with "dancing." "We dance! The girls have been in dance since they were three." Then she went on to show me a few videos of the girls dancing to Disney classics and the Beetles, which were her favourite tunes. The girls' dance acts involved endless twirling while Melanie's voice chimed in the background with positive accolades and applauds for their graceful performances. She ended our conversation with, "They are my world, thank you, I needed this." I wished her well.

Surgery was successful and she was discharged home a few days later to manage her diverting loop colostomy. She was home for a short time when she developed complications and required readmission. Once again palliative care was consulted. After my last positive encounter with her I expected to hear stories about her girls. I had anticipated hearing her two girls greeted her with a new dance number they had rehearsed while she was in hospital. Except she unleashed with, "I smell, I smell. This is disgusting, it is just gross. I cannot believe I brought this smell into my home. I cannot believe I've exposed my girls to this smell." I stood there listening to her outburst, "I showed my husband what it looks like, so now he knows I have a piece of bowel sticking out of my abdomen causing this smell. The gas in this bag just balloons it. The smell, how does one ever get use to that?" She exhaled deeply and tears started flowing down her cheeks. I extended my hand and rested it on her shoulder to comfort her. She whispered under her tears, "Do I smell?" I was all too familiar with those words, as my 80-yearold grandmother lived with that same concern. Odour from a colostomy is a universal concern for many patients regardless of their age or sex. The fear that it will interfere with patients' 
social life and relationships may cause them insurmountable stress and anxiety. Nurses are all too familiar with various odours and know how to normalize them, but the emotional burden patients feel about it can be paralyzing. But what I have found astounding over my years of practice is patient's resilience and learning about the various ways they embrace their fear and find techniques to overcome it. One unconventional approach a patient shared was the use of scented doggy bags inserted inside the ostomy bag that allowed her to empty the stool often and minimize odor.

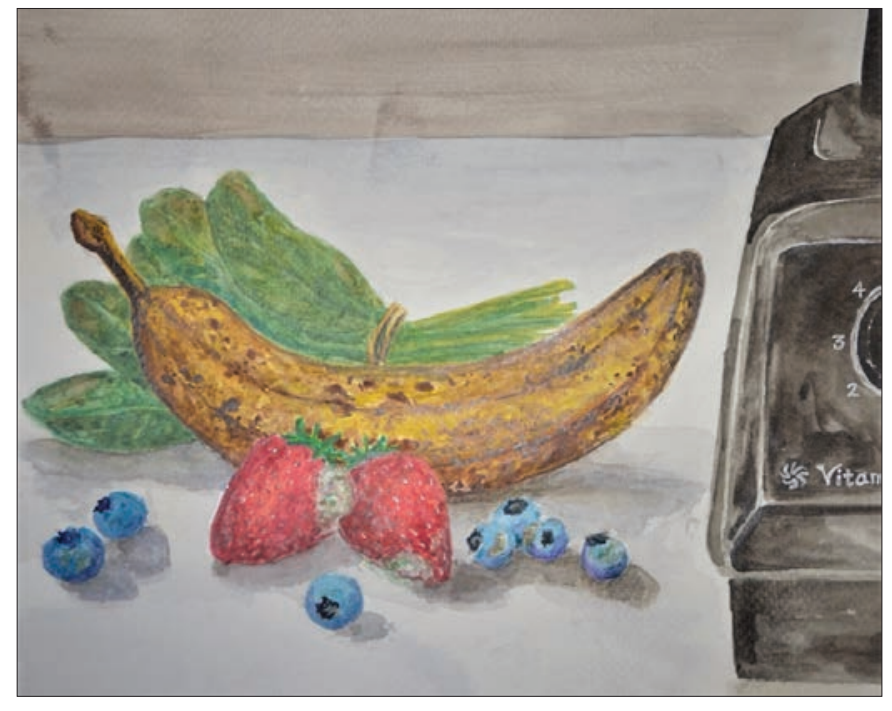

\section{Relationships}

He's a self-made millionaire with little formal education. He invested in property in Toronto and built an empire. He's dying, but pretends he's not. He's yellow, like a banana, and speaks with a faint voice. He smiles when he talks to you and is so cachectic that his white pearly teeth standout. When asked about his disease he says, "They have fixed this problem and that problem, but what I really need is chemo." He's holding on to this next round of chemo like it's his redeemer. The last few rounds of chemo had been postponed due to potential side effects from the chemo, severe mucositis being one of those complications that wouldn't allow him to eat. He has ulcers on the inside of his mouth, a slightly swollen lower lip and pain upon swallowing. He wasn't one to be shy about food or drink, I'm told. For his wife, her priority is maintaining his nutritional intake. His wife cannot appreciate that he's approaching end of life and has fixated on his dietary intake. Her daily routine begins by rummaging through the fridge picking out fruits and vegetables to throw into her Vitamix. Her most recent creation consisted of a little spinach, strawberries, blueberries, kefir, and a whey protein powder. She's been diligent with her daily creations. These drinks are a stroke to her ego, giving her a feeling that she, too, is contributing to his good fight against cancer. Yet, when you observe them at the bedside, they don't speak to each other, they bark at each other. There are no two complementary words strung together in any of their exchanges. He speaks, she barks back; she speaks, he barks back. How unfortunate, I think to myself, to be married to a person for more than 30 years and have such revolting conversations with who is supposed to be your life partner and true love. It's hard not to judge, but that's not something that I could tolerate. As a nurse, it's important that we note our own judgmental thoughts that a scenario brings out in us. It is our professional obligation to provide non-judgmental care and provide positive patient encounters. The way I respond to the patient and his wife in relation to their relationship could have a negative impact on the therapeutic relationship with either of them or with them as a collective. In turn, I might not be able to support them emotionally during this distressful time in hospital. Watching them go back and forth is emotionally wearing and, at times, I want to take one of their sides; but I can't and must remain 'neutral' to try and facilitate some common ground when having conversations about his symptoms and disposition needs. I won't lie, at times the conversation can draw me in, as it would any curious person. They catch their tone periodically, as they are on an inpatient three-bed cancer ward with other patients and families around them. The only divider between their voices and the others is a curtain. There is no privacy whatsoever. Everyone knows their business. I know that for a fact, as the other patients across from Mr. Greg's bed is also a patient of mine, who gives me that look of raised eyebrows and gestures he has something to share. He tries desperately to be discreet, but I always wonder if they can hear him reporting to me. It can put the nurse in a dishonourable position if patients think you're gossiping about them, but the truth of the matter is that patients' neighbors can be their greatest supporters or detractors.

It's amazing to witness these complicated relationships, the co-dependence of a husband and wife with no real mutual reverence for each other's feelings. You wonder if it's the cancer that has changed this relationship or was it always this way. It's hard to ask these questions sometimes. Not every couple is open to talking about their emotional struggles and challenges.

The dialogue between the two didn't change throughout Mr. Greg's hospitalization. What became more and more apparent was that this man's optimism came through his business achievements and not through his family life. He loved the positive appraisals he received from others, the donations he made, and the growing success he saw of his franchise. His family life was empty; it was a mere oath he took a long time ago in his 30s to please his parents. Now, in his dying days, he feels lonely and lacks the sustenance his wife's arms should bring him. He's aware of the consequences of his decisions in life and can only do his best, as he approaches the end of his life, an unhappy married man. 


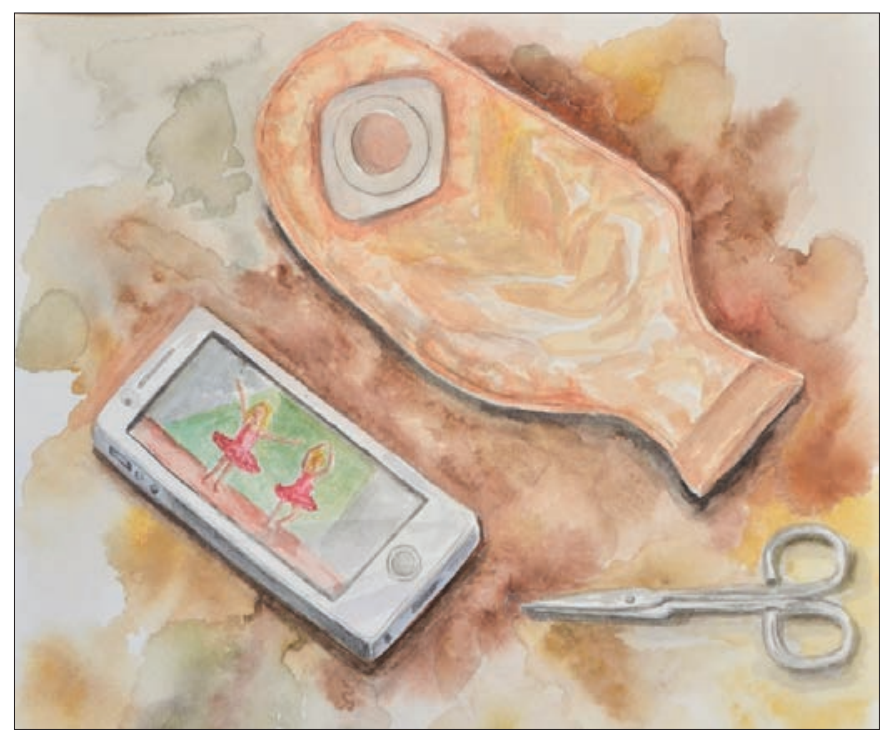

\section{The Power of God}

The words, "the healing hands", greet me each day for three weeks on my daily rounds to assess Olga's pain from AML. Olga has an animated personality, which is so uplifting, and I attribute it to her faith in the good Lord. That vibrant smile and gratitude to be alive another day, along with her blessing for each of the staff and healthcare workers is what infuses through her isolation room. She has not grumbled or gotten angry about her new diagnosis, but has found great relief knowing why she's been in excruciating pain for the last several months. The pain had landed her in two different emergency rooms resulting in one medical differential of rheumatoid arthritis and a daily dose of prednisone, which didn't alter her pain situation. She shares in her medical history all the avenues she tried to find relief; from maximizing her health insurance plan with physiotherapy, massage therapy, chiropractor session and then using non-pharmacological interventions such as a heating pad and warm baths to try and achieve some relief. But all to no avail. Her pain radiated bilaterally down her posterior thighs and into her toes, escalated to a 10 out of 10 on the pain scale, which landed her for a third time in an emergency room and now an admission.

She was a healthcare worker herself and had a lot of experience. After 30 years of looking after other people as a personal support worker, she now found herself losing her independence. When you have seen as much as we have, and now the tables are reversed, the fear of losing any level of independence can be much more profound. She has spent more than half her life caring for others, grooming them every day to look their best, and now she found it emotionally difficult to accept the fact that she needed help. This fear of overburdening the nurses or calling too many times for help was humiliating. She wasn't used to that. Over the week her symptoms improved.

One morning she told me, "Through the grace of God I find myself here and with answers." She said it in a smiling, humbling manner. "I feel his presence and I know he's present because he sends me the healing hands of people like you.
Every person who has touched my life right now is an angel sent from God and I know he will heal me because he sent all of you. I have a lot to live for and I still have purpose. I trusted you from the first few seconds I saw you, you looked at me up and down and you stared right at me. That look on your face told me you studied me and then you left in a flash and when you returned you had an answer."

"I'm a widow and have two children; my husband died just a year ago from a sudden heart attack. My children are still grieving his loss and now they are not going to lose their mother too. They won't lose me." she states with great determination. "I know they won't because God sent me people like you."

"I also have prayer warriors around me. And every time I have any, my phone rings and on the other end are friends and family who blast those prayers. They blow this cancer out of me. I feel their healing powers and their words and that is how I will beat this." The optimism that she illuminates is like no other that I've witnessed before. I attended a lecture on coping with a serious illness and the speaker shared that some people who are religious are also more positive, as they are well connected to a community and have been described as happier. Olga matched that very classic description the professor gave.

One afternoon I had more time after we completed my usual assessment and we started talking. I said, "I feel like you could bust into a dance with the way you move your hands when you talk about this merciful Lord." She said, "Have you heard of Maranda Curtis?” And I politely acknowledged I had not. She found the YouTube video of the song, 'Way Maker', and an angelic voice emerged.

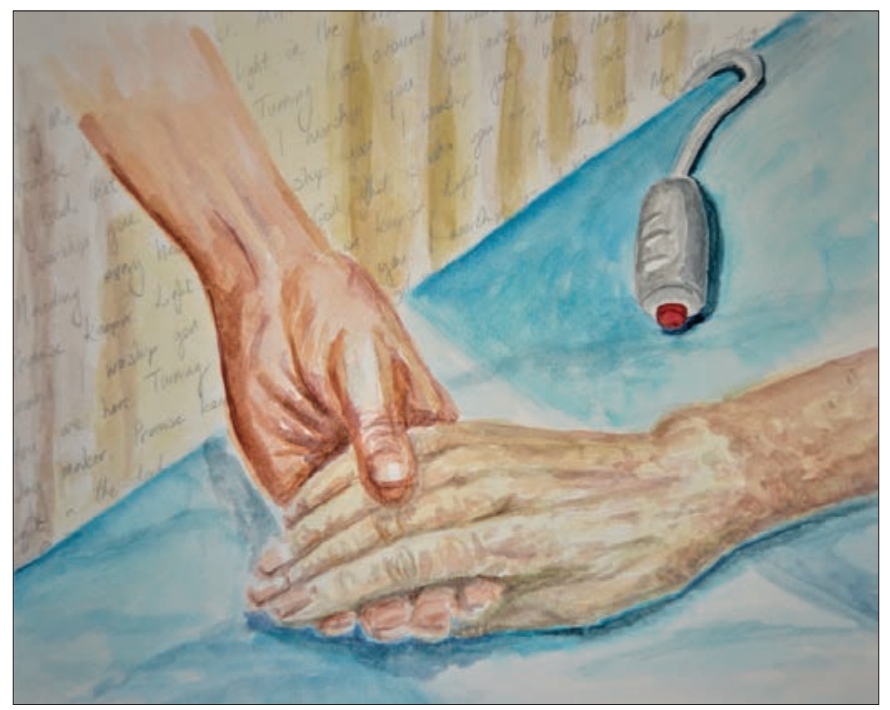

\section{The Second Waltz}

The Second Waltz (Shostakovich) by Andre Rieu is playing in the background during today's rounds on Mrs. Jones. She's struggling with the loss of function of her legs. She presented with a three-day history of inability to walk, unsteadiness on her feet, and lower extremity weakness, 
and urinary incontinence. She was initiated on high-dose intravenous steroids as she waited to be assessed by the spine team.

Looking at this woman you would think she was just an ordinary woman like every other patient I come across; except she wasn't, in my eyes, after my colleague told me more about her life. Mrs. Jones hadn't shared much with me so far. I tried to imagine what this lady looked like in her younger years. Across from me, lying in the hospital bed, was a fivefoot-two, cachectic women with a very stark English accent. She was once one of the top 10 ballroom dancers in her home country before immigrating to Canada. Dancing was in her blood. Spending her precious youth and early adulthood life watching her weight, working on her posture, balance, flexibility, and coordination, all while not knowing that it would one day be taken away. I let the music take me away and I envision her prancing around the ballroom floor with her partner at hand. I pictured her wearing a full-length formal ballgown made of the finest fabric, shiny satin perhaps, and two-inch heels. Looking at her complexion, a bright red gown would suit her well, with her hair neatly pulled back in a low bun and sprayed with at least a half bottle hairspray to keep it in place and also create the illusion of a mirror while she glided across the floor. Her make-up would consist of a matt plum color to draw out those high cheek bones, neatly drawn cat eyes and filled-in eyebrows. I return to the present woman before me, now in a semi-fowlers position. I appreciate her classiness and her daily obsession with her appearance even more. She even makes the blue button-up hospital gown and the sheepskin booties to prevent pressures sores look fashionable.

She finds herself in a surreal experience of not being able to so much as curl her toes. She has metastatic disease from T4-L2 from her uterine cancer. She underwent decompression of L2-L4 in hopes of some improvement in relieving the pressure on the nerves in her spine. Yearning for some progress and a chance to be eligible for rehab, she is now post-op day seven and she hasn't seen any improvement. She describes numbness and tingling in her toes and tries to convince herself that it's some level of recovery.

Her family is struggling too. Her husband was a big fan of hers and 13 years her junior. Their age difference never bothered her, as she herself always appeared and acted younger than her age. She tells me culturally it was frowned upon to marry a younger man, but they did it anyway and, of course, without their parents' approval. He now runs a restaurant in Canada and works seven days a week to provide for his family of four. The children were beside themselves after learning their mother would never walk again. The kids are in their mid-twenties, but she refers to them as babies. I think, who could blame a mother for always viewing her children as her babies. They have been giving her a hard time because she's leaning towards a comfort care approach to care. With great sadness on her face she said, "Why should I bother suffering even more? I cannot be a burden on my children. This disease has already changed their mood. I see the grief they hide behind those eyes." We explore what end of life would look like for her and her family. She chose not to go to the palliative care unit, as the COVID-19 pandemic restricted visitors and so she returned home to bask in the smiles of her family. Once alone, her final words were, "My babies now have learned the most difficult life lesson, that life is temporal and that the person who loves them the most won't be around for them."

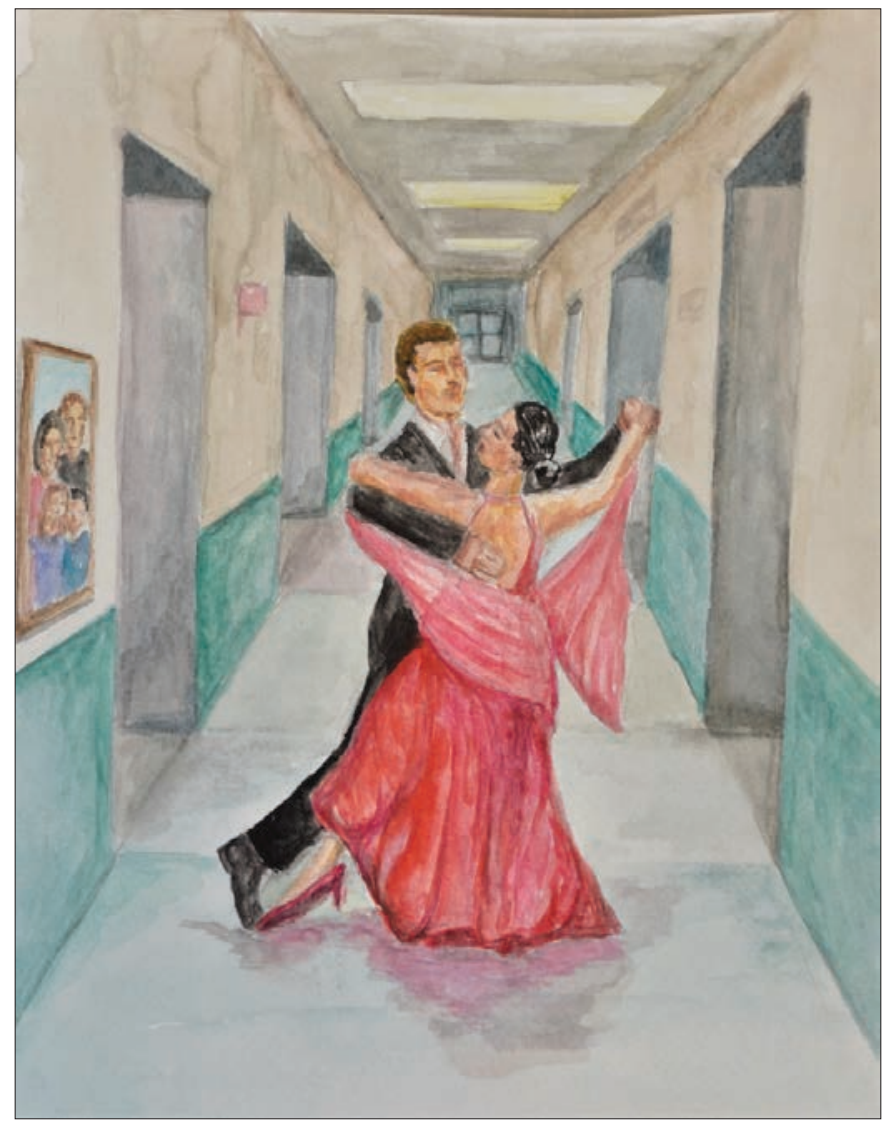

\section{THE VALUE OF ART THERAPY}

Art therapy is a form of psychotherapy that uses visual art making and creative processes to facilitate self-exploration and understanding. Art therapy has been noted to have similar benefits to reflective writing; these creative therapeutic processes can address emotional issues and assist in the expression of thoughts and feelings that might otherwise be difficult to articulate (Canadian Art Therapy Association, 2020). Art therapy can be beneficial for people of all ages to help resolve conflicts, develop interpersonal skills, manage behaviour, reduce stress, increase self-esteem and self-awareness, and achieve insight (American Art Therapy Association, 2017). Art therapy has been shown to be an effective tool for oncology nurses to promote team building, and to manage the symptoms of stress, emotional fatigue, and grief associated with their work (Nainis, 2005).

The art therapist involved in this project, Katherine, created one image for each reflective writing piece with the intention 
of capturing a snapshot from each story. She recounts the experience of this collaboration: "As I read the reflective writings, I found myself visualizing the scenes that were described; I felt deep compassion and empathy for both the patients and the clinician in the stories. I ruminated on the writings and the scenes I imagined, wondering what it was like for the patients and their families, as they journeyed through their illnesses and the care they received. Viewing this reflective process through the lens of an art therapist. I was drawn to using pencil and watercolors, mediums that offer immediacy. I wanted to acknowledge the sometimes sterile and cold hospital setting, the reality of the unpleasantness of disease progression and failing bodies, and the vital relationship that exists between patient and care provider. What struck me most in the reflective writings was how even brief interactions during care can offer great compassion and respect to the patient, and a chance to preserve the patient's dignity. I hope that these images might remind us that small moments of care, which might appear routine on the surface, can hold great power. I hope the images honour the patients' experiences; how they struggle, cope, hope, and develop incredible resiliency in their cancer journey.

\section{CONCLUSION}

As outlined above, my journey with reflective writing came out of a formal process of teaching medical residents. However, I think nurses could benefit from implementing such a process informally, in the form of a personal journal or diary. There is so much that transpires in a day in the life of a nurse, especially when working with patients who have advanced illness. For example, in any given day, I could be involved in a number of the following situations: having an emotional and difficult conversation about goals of care, managing complicated pain and symptoms, and supporting a patient and/or family with grief at end of life; all the while trying to manage my own expectations of responsibility and professionalism. Reflective writing has become my outlet for processing all that I witness, feel, and offer to patients and their families. Having a safe place, free of judgment, to express myself and acknowledge my personal thoughts and feelings is imperative to my mental well-being and work performance.

\section{REFERENCES}

American Art Therapy Association (2017). What is art therapy? https:// www.canadianarttherapy.org/what-is-art-therapy

Bowman, J. (2007). Dealing with job stress: Peer support, time management, and self-care are key. Professional Case Management, 12(5), 252-253.

Brady, D. W, Corbie-Smith, G., \& Branch, W. T. (2002). "What's important to you?" The use of narratives to promote self-reflection and to understand the experiences of medical residents. Annals of Internal Medicine. 137(3), 220-223.

Braun, U. K., Gill, A., Teal, C. R., \& Morrison, L. J. (2013). The utility of reflective writing after a palliative care experience: Can we assess medical students' professionalism? Journal of Palliative Medicine 16, 1-8.
This process allows me to review and monitor my thinking patterns in clinical scenarios when I don't have the comfort level to share them with others.

There are a number of frameworks that can be used to outline one's reflective writing process. All it takes is finding an approach that works for the individual. I have discovered two approaches that are quite simple to follow. Schon's (1983) reflection process outlines engaging in reflecting before, during and after a learning experience. It provides supportive questions for each of the steps within the process. An example of the question posed in each of the steps includes: reflecting before (What do you think might happen?), during the learning experience (Am I dealing with the challenge well?), and after a learning process (Is there anything I would do differently before or during a similar event?).

The second approach is from Gibbs (1988), who describes a cyclical process, which also takes into account the person's feelings as they move through the reflective process. It instructs the individual to describe the scenario, acknowledge his or her feelings, evaluate the good and bad in the experience, analyze what could have been done differently, draw a conclusion, and develop an action plan. Using a framework with prepopulated reflective questions is most helpful in beginning the reflective writing process, as it can support the nurses' thinking and challenge them to think outside their comfort zone.

Given there are a number of reflective writing approaches, it is a matter of finding one that resonates with the individual and becoming acquainted with the process. In time, one does not have to limit themselves to only one process; they can try others.

Lastly, collaborating with the art therapist was a leap beyond the reflective writing process, allowing the art therapist to bring that person's everyday reality to the forefront. The artistic component brought additional healing and mental well-being, as it provided the writer with a visual representation of thechallenging scenarios and a deeper empathetic view of the nurse-patient therapeutic relationship.

Whether you employ reflective writing, art therapy or both as a self-care strategy, all have the ability to improve one's well-being. When nurses function at their peak wellness, they are then able to give their best on the job.

Canadian Art Therapy Association, (2020). About art therapy. https:// arttherapy.org/about-art-therapy/

Chittenden, E. H., \& Ritchie, C. S. (2011). Work-life balancing: challenges and strategies. Journal of Palliative Medicine, 14(7), 870-874.

Clandin, J., Cave, M. T., \& Cave, A. (2011). Narrative reflective practice in medical education for residents: Composing shifting identities. Advances in Medical Education and Practice, 2, 1-7.

Cohen-Katz, J., Wiley, S. D., Capuano, T., \& Baker, D. M., Shapiro, S. (2004). The effects of mindfulness-based stress reduction on nurses' stress and burnout: A quantitative and qualitative study. Holistic Nursing Practice, 18(6), 302-308. 
Driessen, E., van Tartwijk, J., \& Dornan, T. (2008). The self-critical doctor: helping students become more reflective. British Medical Journal, 113, 827-30.

Dyrbye, L. N., Shanafelt, T. D., Balch, C. M. Herrin, J, Wittlin, N. M., et al., (2011). Relationship between work-home conflicts and burnout among American surgeons: A comparison by sex. The Archives of Surgery, 146(2), 211-217.

Ertmer, P. A., \& Newby, T. J. (1996). The expert learner: Strategic, selfregulated, and reflective. Instructional Science, 24, 1-24.

Freeman, B. (2013). CARES: An acronym organized tool for the care of the dying. Journal of Hospice Palliative Care Nursing, 15(3), 147-153.

Gibbs, G. (1988). Learning by doing: A guide to teaching and learning methods. Further Education Unit, Oxford Polytechinic.

Halifax, J. (2014). G.R.A.C.E. for nurses: Cultivating compassion in nurse/patient interactions. Journal of Nursing Education and Practice. 4(1). 121-128.

Jarvis, P. (1992). Reflective practice and nursing. Nurse Education Today, 12, 174-81.

Kearney, M. K, Radhule, B. W., Vachon, M. L. S, Harrison, R. L., \& Mount, B. M. (2009). Self-care of physicians caring for patients at the end of life "Being connected...A key to my survival." American Medical Association, 30 (11), 1155-1164.

Mills, J., Wand, T., \& Fraser, J. A. (2017). Self-care in palliative care nursing and medical professionals: A cross-sectional survey. Journal of Palliative Medicine, 20(6), 625-630.

Moore, J. D., \& Daines, P. (2017). Experiencing renewal as palliative care clinicians through teaching reflective practice: Learning from our learners. Journal of Modern Education Review, 7(1), 64-69.

Nainis, N. (2005). Art therapy with an oncology care team. Art Therapy. Journal of the American Art Therapy Association, 22(3), 150-154.

Pendry, P.S. (2007). Moral distress: Recognizing it to retain nurses. Nursing Economics, 25(4), 217-21.

Pereira, S. M, Fonesca, A. M., \& Carvalho, A. S. (2011). Burnout in palliative care: A systemic review. Nursing Ethics 18(3), 317-326.
Puchalski, C. M. \& Guenther, M. (2012). Restoration and re-creation: Spirituality in the lives of healthcare professionals. Current Opinion in Supportive and Palliative Care, 6(2), 254-258.

Registered Nurses Association of Ontario [RNAO]. (2016). Journaling activity. In C. Forchuk, Arthur Labatt Family School of Nursing course work. University of Western Ontario. https://mharesource. rnao.ca/sites/default/files/2017-10/MHR_WEB_FINAL.pdf

Rokach, A. (2005). Caring for those who care for the dying: Coping with the demands on palliative care workers. Palliative and Supportive Care, 3, 325-332.

Sanchez-Reily, A., Morrison, L. J., Carey, E., Bernacki, R., O’Neill, L., et al. (2013). Caring for oneself to care for others: Physicians and their self-care. Journal Support Oncology, 11(2), 75-81.

Schon, D. (1983). The reflective practitioner: How professionals think in action. Basic Books.

Shanafelt, T. D., Novotny, P., Johnson, M. E., Zhao, X., Steensma, D. P., et al. (2005). The well-being and personal wellness promotion strategies of medical oncologists in the North Central Cancer Treatment Group. Oncology, 68(1), 23-32.

Shapiro, J., Kasman, D., \& Shafter, A (2006). Words and wards: A model of reflective writing and its uses in medical education. Journal of Medical Humanities, 27, 231-244.

Spann, C. (2004). Poet healer: Contemporary poems for health and healing. LAMP.

Stilos, K., Wynnychuk, L., DasGupta, T., \& Daines, P. (2016). Improving end-of-life care through quality improvement. International Journal of Palliative Nursing, 22(1), 430-434.

Stilos, K., \& Wynnychuk, L. (In press). Self-care is a MUST for health care providers caring for the dying. Canadian Oncology Nursing Journal.

Teunissen, P. W., Scheele, F., Scherpbier A. J. J. A., van der Vleuten, C. P. M., Boor, K., et al. (2007). How residents learn: Qualitative evidence for the pivotal role of clinical activities. Medical Education 41, 763-70. 